\title{
Model of Strengthening Human Resources Through the Fisheries Resource Utilization Makassar
}

\author{
Hj. Dahliah, SE. MSi \\ Universitas Muslim Indonesia Makassar, Indonesia \\ bundadahlia@yahoo.com
}

\begin{abstract}
This study aims first to analyze the strengthening of human resource models with variable quality fishing gear insyani resources, involvement in economic activities and the local culture through economic capacity in the utilization of natural resources and the second to analyze fisheries MP3EI program didaaerah Sulawesi economic corridor that has not been synchronized. Implementation of these variables in strengthening human resources in coastal communities. This research was conducted in the coastal area of Makassar, precisely the small island-island Makassar in (two) years. The study population was all fishermen are categorized as poor. Slovin sample was determined with the theory that those who have a poor criterion of 99 respondents.The urgency of research, human resources strength problems, need to be identified at the planning MP3EI program ekonomi.agar growth can go hand in hand between the economic corridor and central Sulawesi. Outcomes research result in models of reinforcement of human resources, strengthening human resources design gran sesuiaThe urgency of research, human resources strength problems, need to be identified at the program ekonomi.agar growth can go hand in hand between the economic corridor and central Sulawesi. Outcomes research result in models of reinforcement of human resources, strengthening human resources design gran sesuia purpose MP3EIresearch initerinspirasi of theory Nurkses (1953), which states that the causes of poverty or weakening of human resources led to the theory of the vicious circle of poverty (Vicions Circle of poverty) put forward by the six elements, namely keterbelakanganataumelemahnya human resources, low investment, omission lack of capital, low savings and low productivity, method used is quantitative method. Model Strengthening human resources with quantitative methods with associated variables later via Path analysis.
\end{abstract}

Keywords: Modeling, strengthening human resources, utilization of fishery resources Path Analisis, the Economic Capabilities, Quality improvement insyani resources, local culture, Poor Families

\section{Introduction}

Background: To accelerate and strengthen economic development in accordance with the potential advantages of sumberda fisheries, accelerated with establishment through strengthening human resources, which is developing. To harness the potential of fishery resources Sulawesi economic corridor for the region are still many obstacles, among others, have not been strong human resources. To strengthen national human resource integrated connectivity locally and globally connected. Natural Resources to Sulawesi economic corridor has not been managed in a comprehensive, yet strong due to its human resources. There are still many poor families in the area of natural resources owned pesisir.sedangkan enough of potential located on Sulawesi corridor.They are komonitas fishermen, today the power problem of human resources is an important issue to be discussed and addressed. The problem of poverty is not only hit the asiancomonity but also hit the entive world commonityUrgensipenelitian associated with, the problem of human resource strength, need to be identified at the planning ekonomi.agar growth MP3EI program can be run on economic corridor Sulawesi (Poli, 2007; McKay, 2003). Milbourne (2004) and Mahsen \& Water (2002) stated that, during the New Order regime, Indonesia's development is the focus of economic development, characterized by economic growth with benchmark high level of GDP per capita each year. This pattern is still conventional as it aims to menciptahan "trickledown effect" of development results to the public at large. The amount of the govermantas'forgotten other social problems that arise such as the issu of humanresources is still weak unemployment inequality inincome distribution, as well asenviromentaldamage.Coastal communities cannot be separated from the development of the city due to coastal development is also an integral part of urban development. To achieve these objectives pursued optimizing the utilization of fishery resources. It is considered to be very precise and strategic reasons that the fisheries sector is one of the natural resource potential which should be utilized optimally for the prosperity of the people. This is supported by the 
SupportCoastal communities cannot be separated from the development of the city due to coastal development is also an integral part of urban development. To achieve these objectives pursued optimizing the utilization of fishery resources. It is considered to be very precise and strategic reasons that the fisheries sector is one of the natural resource potential which should be utilized optimally for the prosperity of the people. This is supported by the MP3EI support (Fao, 2005).

Coastal communities can not be separated from the development of the city due to coastal development is also an integral part of urban development. To achieve these objectives pursued optimizing the utilization of fishery resources. It is considered to be very precise and strategic reasons that the fisheries sector is one of the natural resource potential which should be utilized optimally for the prosperity of the people which is supported by the Hancook \& Tina (2010). How strengthening human resources in the implementation of these variables in the utilization of fishery resources are used for poverty reduction.Is the strategy model through the variable quality of human resources, variable peroduksi tools, and variable involvement of economic activity, and local culture, variable economic capacity can memerkuat human resources. How Implementation of these variables in strengthening human resources (Godwin, 2010; Giffin, 1999).

Research Purposes: Based on the formulation of the problem above, the objectives to be achieved at the focus of economic growth in developing dan study are:

To analyze the implementation of these variables in strengthening human resources .

Benefits of research: This research is expected to provide a real contribution to the development of Natural Resource Economics, strengthen human resources can make Indonesia as one of the world's largest producer of fishery. With the model approach to strengthen human resources are used is expected to provide input for the government in regional autonomy

- To mengidentifasi variables, can strengthen human resource development in the growth, strengthen HR

- To analyze the behaviors of Human resources in coastal communities.

- To identify the variable quality of human resources, variable peroduksi tools, and variable involvement of economic activity, and variable economic capacity to strengthen human resourcesexpected to provide input for the government in regional autonomy to be used as a study and consideration in formulating development policies utilization of Natural Resources coastal areas, especially for coastal communities to be a strengthening of human resources and also can be used as a model in support.

Urgency Research: The urgency of research, human resources strength problems, need to be identified in the planning of economic growth, between economic corridor and central Sulawesiresearch initerinspirasi of theory Nurkses (1953) and Daniels (2002) which states that the causes of poverty or weakening of human resources led to the theory of the vicious circle of poverty (Vicions Circle of poverty) put forward by the six elements, namely retardation, low investment, omission lack of capital, low savings and productivity low, the method used is quantitative method. Need to identify the planning of economic growth, to support the MP3EI program to strengthen human resources. But the theory Nurkse not include elements of local culture, while the theory of MC Keland in Kuntjaraningrat, local culture on a high mentality assess the quality and accuracy requires a high rate of cultural value orientation results from the work of humans. Cultural values developed by every nation that wants to increase the intensity of pressure trying to enhance its production and become more prosperous.Outcomes research. Grand design reports use models corresponding strengthening of human resources development program purpose.Need to identify the planning of economic growth, to support the development program, program to strengthen human resources . But the theory Nurkse not include elements of local culture, while the theory of MC Keland in Kuntjaraningrat, local culture on a high mentality assess the quality and accuracy requires a high rate of cultural value orientation results from the work of humans. Cultural values developed by every nation that wants to increase the intensity of pressure trying to enhance its production and become more prosperous.Outcomes research. Grand design reports use models corresponding strengthening of human resources . 


\section{Literature Review}

Efforts Strengthening human resources is one of the MP3EI program: During this time, various efforts have been made by the government to strengthen human sumberday among other things tackle and eradicate poverty, formulating standards poverty line and construct maps pockets of poverty. Beyond that, there are very few programs have been developed and implemented in the field. For example, is to continue to spur national economic growth, provide credit facilities for the poor, among others through the provision of financial assistance IDT, program Tekesra - Kukesra, KURK, build infrastructure in perukiman slum, the development of the development model integrated area, including implementing, and improving the quality of programs development.For most, the various aid and government programs that have been pursued are quite useful. However, it must be recognized that poverty reduction efforts undertaken until now still not produce satisfactory results. There are still many residents of Indonesia, both in rural and urban, who lives wrapped poverty. On the other hand, it is also undeniable fact, that although the number of poor people decreased, but the gap is in many ways even more broadly. During this time, the government's approach in dealing with poverty, both at the national, regional, and local, generally is to adopt a purely economic approach, which is often not ignore the role of culture and the local community context. There is a strong impression that the government in the eyes of the poverty problem seems to only be understood as a problem of lack of income. Highly visible also in various programs launched by the government umunnya just trying to provide assistance in the areas of capital, provide subsidies, and the lik(Danani \& Islam, 2002; fao, 2012; Ellis, 1984).

Causes of Poverty: Poli (2007), Chinner \& Polnac (2004) and Milbourne (2004) states that the underlying causes of poverty, poverty theoretically be divided into two categories. First, the nature of poverty, the poverty that arise as a result of the resources are scarce in number and / or because of the level of technological development is very low. Factors that cause a society to be poor is naturally do exist, and not that there will be groups or individuals in the community who are poorer than others. May be in a state of poverty will naturally be differences of wealth, but the impact of these differences will be softened or eliminated by the presence of traditional institutions, such as the pattern of relationships patronclient, spirit of mutual cooperation, and the like are functional to dampen the possibility of social jealousy. Secondly, the artificial poverty, the poverty that occurs due to the existing social structure makes members or community groups did not control the economic means and facilities evenly.Thus, some community members remain poor despite the fact that the total amount of production generated by these communities if divided equally able to release all members of the community out of poverty. Artificial poverty in many respects occurs because an individual or family member lazy to work, or because of persistent pain. In contrast to the perspective of modernization that tends sentenced poverty comes from the weak work ethic, he did not have ethical self-employment, or because a culture unaccustomed to hard work, can be referred to as structural poverty.

Soemardjan (1984), Mikolic (2009), Adisasmita (2013) and Degnbol (2006) explained that the definition of structural poverty is the poverty suffered by some segments of society because the social structure was not able to participate using the resources of actual income available to themVarious poverty alleviation programs and social safety net programs vary, but in fact almost the same substance, namely providing capital flow to poor people and ask them to work harder to empower themselves. For the short term, the provision of economic assistance is beneficial. However, for a real long-term economic aid that will not solve the problem of poverty completely. Much evidence shows that the provision of economic aid alone was actually spawned newproblems-problems that are not intricately. In fact, it is not impossible obtaining capital assistance loan will only constitute the starting point for all kinds of other problems and the destruction of the poor effort.This statement can be caused by various factors as mentioned above. When observed closely, the development of regional development thinking for instance of coastal areas, has not been touched by the improvement of the physical life on the island where the population is Muslim, for example, improvement of living standard in the field of teachers and health. Thought as presented by Arraiyah (2007), Gordon (1954) and Gregor (2008) that the presence of other factors such as local culture should be able to touch the earnings improvement Siri'naPacce fishermen because it is the culture of Makassar. It is thus important and valuable local cultur' so that the existence of a man in her life is largely 
determined by local cultur' and for those who are not memiliknya considered nothing more than animals (Daniel, 2002; Bruk \& Danzer, 2011; Barro, 1995; Denner, 2003; Coulthard, 2013).

\section{Methodology}

This research study was conducted in the coastal city of Napier. While the time is used in this study is is for 4 (four) months. The population in this study are those who have a poor criterion as described in the background, then the $\mathrm{n}$ number of samples to be taken based on the formula Slovin and obtained a sample of 100 respondentsAnalysis techniques in penelitianini is the path analysis with Sobel Test on testing approach mediation between variables. In accordance with the objectives of the research conducted can be categorized as an explanatory research, the research aims to find an explanation for the causal relationship or influence the relationship between variables with other variables through hypothesis testing (Umar, 2004; Bailey, 1994; Doclus, 2009). Variables in this study are variable Strengthening the quality of human resources (X1), availability of fishing gear Fish (X2), Involvement in Economic Activity (X3), Local Culture (X4), Ability Economics (Y1), Reduction of Number of poor families (Y2) following this:

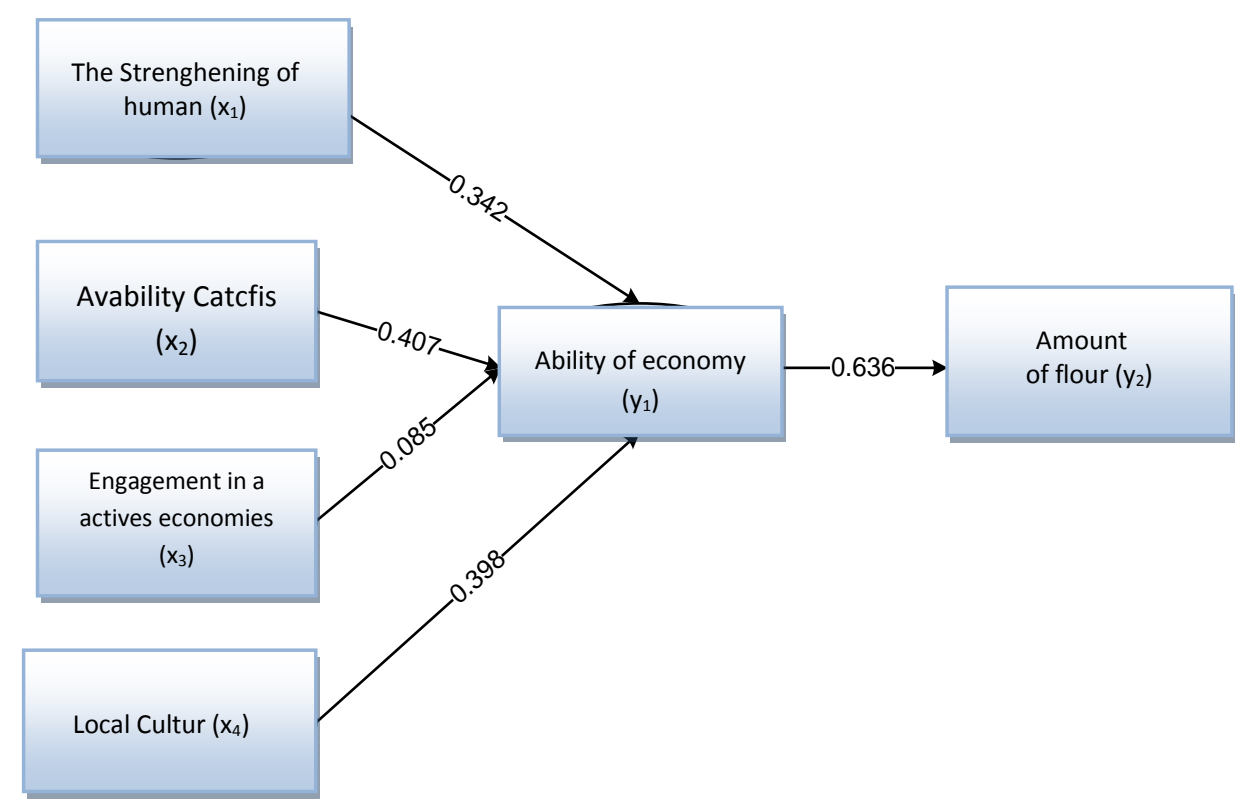

Constructs were built as in the diagram above path can be divided into two groups, namely: construct exogenous consisting of Increased Resources Human (X1), availability of fishing gear (X2), involvement in the Economic Activity (X3) and the Local Culture (X4 ), as well as constructs comprising endogenous variables Economic Capabilities (Y1), and the Reduction of Number of poor. Constructs were built as in the diagram above path can be divided into two groups, namely: construct exogenous consisting of Increased Resources Human (X1), availability of fishing gear (X2), involvement in the Economic Activity (X3) and the Local Culture (X4), as well as constructs comprising endogenous variables Economic Capabilities (Y1), and the Reduction of Number of poor families (Y2). Construct exogenous (exogenous constructs comprising endogenous variables Economic Capabilities (Y1), and the Reduction of Number of poor families (Y2). Construct exogenous (exogenous constructs), known also as the source variable is a variable that is not predicted by other variables in the model. Construct endogenous (endogeneous constructs), is a variable whose value is determined in the model. Furthermore, the picture above, can also be expressed in the form of the following equation :

1. $\mathrm{Y} 1=\mathrm{X} 1 \mathrm{P} 1+\mathrm{P} 2+\mathrm{P} 3 \mathrm{X} 2 \mathrm{X} 3+$ ×2. $\mathrm{Y} 1 \mathrm{Y} 2=\mathrm{P} 5+\varepsilon 2$ 
Step Two : Examination of the assumptions underlying the path analysis, among others:

a. The relationship is linear and additive models. Examination of linearity assumption can be seen from the plot remnant. According to Baulch (2000), Barro (1995) and Buriel (1994), one of the goals was to determine the residual checks whether the variables included in the model might not be linear. If the remnant were scattered on the value of the forecast shows a random pattern, then the data does not indicate to abnormalan, so that the relationship between variables can be said to be linear.

b. Any residual data model of the normal spread. The normal distribution is a theoretical distribution and continuous random variables. To test whether the sample is a normal distribution type

then used the test Kolmogorov -Smirnov Goodness of fit test with the testing criteria if the number of significance (sig.) $>0.05$, then the normal distribution of data .

c. Variables measured without error (valid and reliable).

The third step, Path coefficient calculation (estimation parameters): states that essentially the path coefficient is the regression coefficient standardized (Beta Coefficient) is the regression coefficients were calculated on the basis of data that has been set in a number of raw or Z -score (the data set with values mean $=0$ and standard deviation $=1$ ). Standardized path coefficient (standardized path coefficient) is used to describe the influence of independent variables (exogenous) to the other variables are treated as dependent variables (endogenous). According Marquis (1996), Munir (2002) and Gregor (2008) coefficient of Y to X (Byx), will be equal to the coefficient of $X$ to $Y(B X Y)$, also equal to the correlation coefficient ( $r$ xy) . So that the path coefficientcalculation using correlation matrix, or by looking at standardized regression coefficients (beta coefficient), essentially the same value.

1. $\mathrm{Y} 1=\mathrm{P} 1 \mathrm{X} 1+\mathrm{P} 2 \mathrm{X} 2+\mathrm{P} 3 \mathrm{X} 3+\mathrm{P} 4 \mathrm{X} 4+\varepsilon 1$

2. $\mathrm{Y} 2=\mathrm{P} 5 \mathrm{Y} 1+\varepsilon 2$

The second step: an examination of the assumptions underying the path analisis.

a. Relationships in the model is linier andEdit

Constructs were built as in the diagram above path can be divided into two groups, namely : construct exogenous consisting of Increased Resources Human(X1), availability of fishing gear (X2), involvement in the Economic Activity (X3) and the Local Culture (X4), as well as constructs comprising endogenous variables Economic Capabilities (Y1), and the Reduction of Number of poor families (Y2). Construct exogenous (exogenous constructs), known also as the source variable is a variable that is not predicted by other variables in the model. Construct endogenous (endogeneous constructs), is a variable whose value is determined in the model. Furthermore, the picture above, can also be expressed in the form of the following equation :

1. $\mathrm{Y} 1=\mathrm{X} 1 \mathrm{P} 1+\mathrm{P} 2+\mathrm{P} 3 \mathrm{X} 2 \mathrm{X} 3+\mathrm{X} 4+\mathrm{P} 4 \varepsilon 1$

2. $\mathrm{Y} 1 \mathrm{Y} 2=\mathrm{P} 5+\varepsilon 2$

Step Two: Examination of the assumptions underlying the path analysis, among others: Relationships in the model is linear and

Step Three, Path coefficient calculation (estimation parameters): Solimun (2002), Taringann (2013) and Gordon (1954) mentions that $\mathrm{ON}$ is essentially Coefficient Line is a regression coefficient standardized (Beta Coefficient) is the regression coefficients were calculated on the basis of data that has been set in a number of raw or Z-score (the data set with values mean $=0$ and standard deviation $=1$ ). Standardized path coefficient (standardized path coefficient) is used to describe the influence of independentthen used the test Kolmogorov-Smirnov Goodness of fit test with the testing criteria if the number of significance (sig.) $>0.05$, then the normal distribution of data.

c. Variables measured without error (valid and reliable).

Step Three, Path coefficient calculation (estimation parameters): Cristope (2003), Ferdinand (2000), Borroach-Vani (2005), Bruck (2011) and Bruk-Meir (2008) mentions that ON is essentially Coefficient Line is a regression coefficient The standardized (Beta Coefficient) That coefficient regression The calculated database Of Which Has set in default numbers OR Z-score (data The set WITH Value mean $=0$ and standard 
deviation = 1). Line The standardized coefficients (path coefficients standard) husband used to review describes the effect of free variables (exogenous) variable Against The enforced lay AS Tied variables (endogenous).* According Supranto (2004), Gozali (2009), Cristope (2003), Hair et al. (1998) and Barrow (1995) beta coefficient From Y against X (Byx), will equally WITH coefficient From X to Y (BXY), ALSO WITH same correlation coefficient ( $\mathrm{r}$ xy). So the calculation coefficient WITH Strip using correlation matrices, or ON WITH Seeing The standardized regression coefficients (beta coefficient), ON is essentially the same value.

The fourth step, testing the significance of the influence of The ADA hearts Path analysis: Test the significance of direct influence WITH THE consult $t$ value $t$ table. If the value $t<t$ tablethen $\mathrm{H} 0$ accepted From Value Ha rejected, OR NO significant effect Direct From Free variables on the dependent variable. Conversely, if the value $t>$ From Value $\mathrm{T}$ table then HO rejected Ha accepted OR NO significant effect Direct From Free variables on the dependent variable.

Step Five: Check the validity of the model: Examination of the validity of the model using the coefficient of determination MAY whole. The The amount of data that can be explained Model Diversity Posted measured WITH formula:

R2M = 1 - P2e1 P2e2 ....P2ep

Against the same interpretation R2M WITH interpretation coefficient of determination (R2) ON regression analysis. The model is said to be valid if it has the precision and High Accuracy. Size Model Accuracy is coefficient of determinatio(R2) with a value ranging from 0 to 1.In this study, examination of the validity of the model using rules triming theory.

\section{Results}

Pengujian Validity and Reliability Research Instruments: The following table is presented esting the validity and reliability of research instrument in each variable

Table 1: Test Result and Reliability

\begin{tabular}{lllllll}
\hline Indikator & X1 & \multicolumn{3}{c}{ X2 } & X3 \\
\hline 1 & $\mathrm{X} 1.1$ & 0.740 & $\mathrm{X} 2.1$ & 0.725 & $\mathrm{X} 3.1$ & 0.764 \\
2 & $\mathrm{X} 1.2$ & 0.662 & $\mathrm{X} 2.2$ & 0.850 & $\mathrm{X} 3.2$ & 0.769 \\
3 & $\mathrm{X} 1.3$ & 0.676 & $\mathrm{X} 2.3$ & 0.712 & $\mathrm{X} 3.3$ & 0.668 \\
4 & $\mathrm{X} 1.4$ & 0.742 & $\mathrm{X} 2.4$ & 0.779 & $\mathrm{X} 3.4$ & 0.774 \\
5 & $\mathrm{X} 1.5$ & 0.724 & $\mathrm{X} 2.5$ & 0.797 & $\mathrm{X} 3.5$ & 0.753 \\
6 & & & & & $\mathrm{X} 3.6$ & 0.719 \\
Alfa Cronbach & 0.751 & & 0.830 & & 0.834 & \\
Indikator & $\mathrm{X} 4$ & & $\mathrm{Y} 1$ & & $\mathrm{Y} 2$ & \\
1 & $\mathrm{X} 4.1$ & 0.751 & $\mathrm{Y} 1.1$ & 0.839 & $\mathrm{Y} 2.1$ & 0.824 \\
2 & $\mathrm{X} 4.2$ & 0.829 & $\mathrm{Y} 1.2$ & 0.430 & $\mathrm{Y} 2.2$ & 0.791 \\
3 & $\mathrm{X} 4.3$ & 0.817 & $\mathrm{Y} 1.3$ & 0.824 & $\mathrm{Y} 2.3$ & 0.793 \\
4 & & & $\mathrm{Y} 1.4$ & 0.828 & & \\
Alfa Cronbach & 0.716 & & 0.698 & & 0.711 & \\
\hline
\end{tabular}


Table 2:Value Loadingfactor on the respective respectiveVariabels

\begin{tabular}{lllllll}
\hline Indikator & X1 & & X2 & \multicolumn{3}{c}{ X3 } \\
\hline 1 & $\mathrm{X} 1.1$ & 0.741 & $\mathrm{X} 2.1$ & 0.732 & $\mathrm{X} 3.1$ & 0.768 \\
2 & $\mathrm{X} 1.2$ & 0.653 & $\mathrm{X} 2.2$ & 0.863 & $\mathrm{X} 3.2$ & 0.787 \\
3 & $\mathrm{X} 1.3$ & 0.694 & $\mathrm{X} 2.3$ & 0.703 & $\mathrm{X} 3.3$ & 0.643 \\
4 & $\mathrm{X} 1.4$ & 0.758 & $\mathrm{X} 2.4$ & 0.781 & $\mathrm{X} 3.4$ & 0.763 \\
5 & $\mathrm{X} 1.5$ & 0.698 & $\mathrm{X} 2.5$ & 0.784 & $\mathrm{X} 3.5$ & 0.751 \\
6 & & & & & $\mathrm{X} 3.6$ & 0.734 \\
Indikator & $\mathrm{X} 4$ & & $\mathrm{Y} 1$ & & $\mathrm{Y} 2$ & \\
1 & $\mathrm{X} 4.1$ & 0.773 & $\mathrm{Y} 1.1$ & 0.854 & $\mathrm{Y} 2.1$ & 0.864 \\
2 & $\mathrm{X} 4.2$ & 0.814 & $\mathrm{Y} 1.2$ & 0.134 & $\mathrm{Y} 2.2$ & 0.780 \\
3 & $\mathrm{X} 4.3$ & 0.813 & $\mathrm{Y} 1.3$ & 0.897 & $\mathrm{Y} 2.3$ & 0.766 \\
4 & & & $\mathrm{Y} 1.4$ & 0.911 & & \\
\hline
\end{tabular}

From the table above shows that all the correlation value of each indicator and the item is above 0.3 . Thus, the overall indicator and the item has a valid question. While the obtained Cronbach alpha values above 0.6 for all variables so that it can be concluded that the instrument has a valid research data..Factor Analysis Results.Loading factor values indicate the weight of each indicator as a measure of the respective msing latent variables. Indicator with the largest factor loading indicates that the indicator measuring variables such as strongest (dominant). Factor analysis is presented above in table 2. Strengthening the variable quality of human resources (X1) was measured with five indicators of Job Training (X1.1), Education (X1.2), apprenticeship (X1.3), Assistance (X1.4) and Special Training (x1.5), Loading factor of the highest value is obtained that the most dominant form Accompaniment indicator Increased variable.Variable availability fishing gear (X2) was measured by four indicators ie Capture tool type (X2.1), capacity of fishing gear (X2.2), Working Capital (X2.3), Investment Credit (X2.4) and Grant (X2.5). Loading factor of the highest value is obtained that the capacity of fishing gear indicator(X2.2) form the most dominant variable availability.Variable involvement in economic activity (X3) is measured by six indicators, namely clarity Prospects (X3.1), Certainty Market (X3.2), Dkungan product design assistance (X3.3), Customer Certainty (X3.4), Place auction fish (X3.5) and Peranjakan / Retribution (X3.6). Loading factor of the highest value obtained assurance that the market indicator (X3.2) the most dominant form Involvement variables.The local culture variable (X4) is measured by three indicators of Mutual Cooperation (X4.1), Ritual Ceremony (X4.2) and Siri' napacce (X4.3). Loading factor of the highest value obtained that indicator Ritual Ceremony (X4.2) form the most dominant variable Local Culture. The ability of economic variables (Y1) was measured by four indicators ie Savings (Y1.1), Revenue (Y1.2), Education (Y1.3) and Network (Y1.4). Loading factor of the highest value is obtained that the indicators Network ( Y1.4 ) the most dominant form of Economic Capabilities variables.Variable reduction amount for poor families (Y2) is measured by three indicators of Economic Conditions (Y2.1), Family Health (Y2.2) and Education/Religious Family (Y2.3). Loading factor of the highest value obtained that indicators Economic Conditions (Y2.1) the most dominant form of variables Reduction Amount Poor Family.

Testing Assumptions in Path Analysis: Linearity Testing the relationship between variables in this study using the Curve Fit method showed that all influence in the form of a linear model. Next to test the assumption of normality in the residuals of each equation in the analysis path. Sig Kolmogorov Smirnov for two equations each for 0894 and 0895 are all greater than 0.05 , so that the residual normality assumptions are met

Path Analysis Results: The first stage in the path analysis is testing the goodness of fit models. The coefficient of determination total amounted to $85.96 \%$. This indicates the diversity of data that can be explained by the model is equal to $85.96 \%$, or in other words, the information contained in the data $85.96 \%$ can be explained by the model. While the $14: 04 \%$ explained by other variables (which is not contained in the model).Hypothesis testing is done by $\mathrm{T}$ - statistics in each lane partial direct effect. Results of the analysis is 
complete, the results of the analysis contained in the path, can be found in Annex 3. The following table presents the results of hypothesis testing direct influence (Gozali, 2009; Ellis, 1984; Gainer, 2010).

Tabesl 3:testing results influence Path model

\begin{tabular}{|c|c|c|c|c|}
\hline Relations Variable & Koefisien & T-Statistik & P-value & Conclucion \\
\hline $\begin{array}{l}\text { The strengthening of human resources (X1) } \\
\text { agains the ability of the economy (Y1) }\end{array}$ & 0.385 & 3.117 & 0.005 & Signifikan \\
\hline $\begin{array}{l}\text { Avaliability of the catch fish (X2) agains the } \\
\text { ability of the economy (Y1) }\end{array}$ & 0.502 & 3.529 & 0.002 & Signifikan \\
\hline $\begin{array}{l}\text { Engagement in activities economic (X3)agains } \\
\text { the ability of the economy (Y1) }\end{array}$ & 0.058 & 0.430 & 0.671 & $\begin{array}{l}\text { Non } \\
\text { Signifikan }\end{array}$ \\
\hline $\begin{array}{l}\text { Local cultture (X4) agains the ability of the } \\
\text { economy(Y1) }\end{array}$ & 0.180 & 1.173 & 0.252 & $\begin{array}{l}\text { Non } \\
\text { Signifikan }\end{array}$ \\
\hline $\begin{array}{l}\text { Ability of the economy (Y1) to reduction of the } \\
\text { amount of poor family (Y2) }\end{array}$ & 0.602 & 3.987 & 0.000 & Signifikan \\
\hline
\end{tabular}

In Grafphic Analyses of Presented as Follows Testing Results

Based on the table and the picture above, the results of hypothesis testing direct influence in the inner models are as follows:

- Testing the direct influence of Improving the quality of human resources (X1) on the ability of Economics (Y1), the value of the path coefficient of 0.385 , with the value of the $\mathrm{T}$ - statistic of 3.117 , and $\mathrm{p}$-value of 0.005 . Because the $\mathrm{T}$ - statistic values $>1.96$ and $\mathrm{p}$ - value $<0.05$, then there is

- Testing direct influence between the availability of fishing gear (X2) on the ability of Economics (Y1), the path coefficient values obtained for 0502 , with the value of $T$-statistics for 3529 , and a p -value of 0.002 . Because the $T$ - statistic values $>1.96$ and $p$ - value $<0.05$, then there is a significant direct effect between the availability of fishing gear on the ability of Economics (Y1).

- Testing the direct influence of involvement in economic activity (X3) against the ability of Economics (Y1), the value of the path coefficient of 0.058 , with the value of the T - statistic of 0.430 , and $\mathrm{p}$-value of 0671 . Because the $T$ - statistic values $<1.96$ and pvalue $>0.05$. Then there is no significant direct influence between involvement in economic activities to the ability of Economics (Y1). That is, the intensity of the involvement in economic activity did not affect the intensity of the economic capacity (Y1

- Testing the direct influence of the local culture (X4) against the ability of Economics (Y1), the value of the path coefficient of 0.180 , with the value of the $\mathrm{T}$ - statistic of 1.173, and $\mathrm{p}$-value of 0.252 .Because the $\mathrm{T}$ - statistic values $<1.96$ and $\mathrm{p}$ - value $>0.05$, then then there is no significant direct influence on the ability of the local Cultural Economy ( Y1)

- Testing the direct influence of the Economic Capabilities (Y1) to the reduction amount for poor families (Y2), the path coefficient values obtained for 0602 , with the value of T -statistics for 3987, and a $\mathrm{p}$-value of 0.000 . Because the $\mathrm{T}$ - statistic values $>1.96$ and $\mathrm{p}-$ value $<0.05$, then there is a significant direct effect between the ability of Economics (Y1) to the reduction amount for poor families (Y2).The following table presents the results of hypothesis testing indirect effect. 


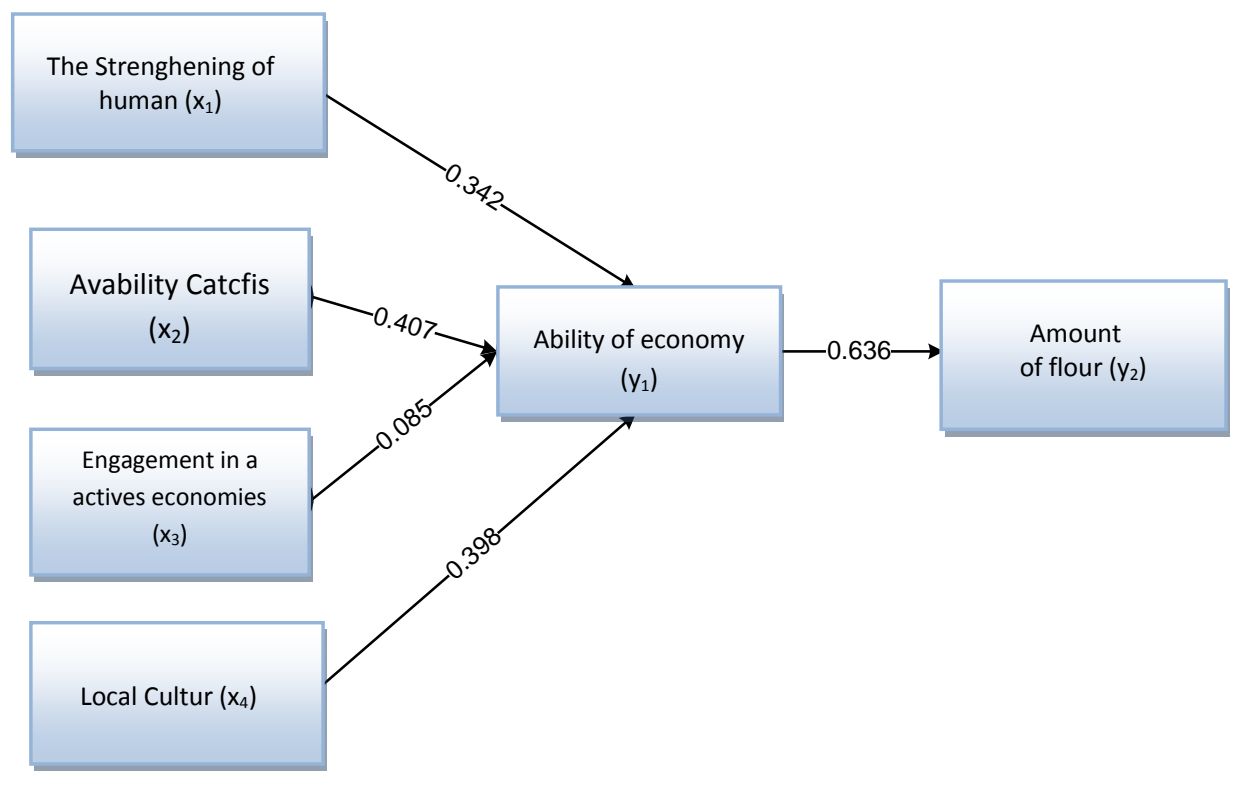

Table 4:Testing Influence Indirect Result Path Model

Relations Variables

\begin{tabular}{lllll} 
Independen & Dependen & Intermediary & $\begin{array}{l}\text { Infirect } \\
\text { Induence Coeficient }\end{array}$ & Conclution \\
\hline $\mathrm{X} 1$ & Y2 & Y1 & 0.215 & Significant \\
X2 & Y2 & Y1 & 0.302 & Significant \\
X3 & Y2 & Y1 & 0.035 & Non Significant \\
X4 & Y2 & Y1 & 0.108 & Non Significant \\
\hline
\end{tabular}

Based on the table above, there are six indirect effect with the following results :

- The indirect effect between Improving the quality of human resources to the reduction in the number of poor families through the Economic ability, coefficient indirect effect of0215. Due to the direct effect of which form a significant indirect influence, it can be inferred the existence of a significant indirect effect between Improving the quality of human resources to the reduction in the number of poor families through the Economic Capabilities

- The indirect effect between availability of fish toward fishing gear reduction in the number of poor families through the Economic ability, coefficient indirect effect by 0302. Due to the direct influence that shape both significant indirect influence, it can be inferred the existence of a significant indirect effect between availability of fish toward fishing gear reduction in the number of poor families through the Economic Capabilities

- The indirect effect between Involvement In Economic Activity of the reduction in the number of poor families through the Economic ability, coefficient indirect effect of

- 0035. Since one of the direct effect of forming influence langsusng not insignificant, it can be concluded not terdaoat significant indirect influence between Involvement In Economic Activity of the reduction in the number of poor families through the Economic Capabilities.

- 4.There are significant directinfluence between the local culture of the ability of Economics (Y1). That is, the intensity of the local culture does not affect the level of economic capability.

- There is a significant direct effect between the ability of Economics (Y1) to the reduction amount for poor families (Y2). The coefficient is positive, indicating the higher ability of Economics (Y1), the higher the reduction amount for poor families (Y2).

- There is a significant indirect effect between muta Strengthening human resources to the reduction in the number of poor families through the Economic Capabilities. 
- There is a significant indirect effect between availability of fish toward fishing gear reduction in the number of poor families through the Economic Capabilities.

- There are significant indirect influence between Involvement In Economic Activity of the reduction in the number of poor families through the Economic Capabilities.

- There are significant indirectinfluence between Local Culture of the reduction in the number of poor families through the Economic Capabilities

\section{References}

Arraiyah. (2007). Menoropong phenomenon Poverty: Assessing Perspective of the Qur'an. Student Library Publishers

Adisasmita. (2013). Theory of economic development, economic growth and growth in the region, $1^{\text {st }}$ edition, publisher graha science jokyakarta

Baulch, B. (2000). Economic Mobility and Poverty dynamics in developing countries. Journal of Development Studies, 36(6), 1-24.

Bailey, C. (1994). EmpoloymentLabourProduktivity an in comein smile fisher of South and southeas Asia. In socio Economic issues in costal fishier management IPFC (pp24-45)-Fasipic Fisheries commussion Bangkok Thaeland,november 23-26.1993.

Cristope, B. (2003). When Fishery Rhymes with Poverty: A First Step Beyond the Old Paradigm on Poverty in Small-Scale Fisher www,elsevier/ locate/ clenyca.

Borroah-Vani, K. (2006). China and India: Income inequality and poverty nort and south of the Himalayas. Journal of Asian Economic, 17, 797-817. Availeble online at.www.sciencedirct.com

Barro, R. J. (1995). Economic Growth. International Edition 1995.

Bruck,T. \& Danzer, A. M. (2011). Relativ Deprivation relativ Satisfection, and antitur toward mirand Efidence from Ukranie (2011). Journal Economic Systems, 35(2), 189-207.

Brukmeir, K. \& Larsen, C. H. (2008). Swedis Coastal Fisheries-From conflict mitigation to Participatori Management. Marine Policy, 32, 201-211.www.sciencedirec.com

Buriel, R. (1994). Integration with Tradisional Mexican-american cultur and sosiocultural adjustman. In.J.Matinez \& Rmendoza (Edz), Chicano psyhologi (pp-135 New York: Academic Press.

Chinner, J. E. \& Polnac. (2004). Poverty Perceptions and Planning; Why SocioeconomicsMatter in The Management of Mexician Reefs: www, elsevier/locate/cloenycha.

Coulthard, S. \& Johnson, D. (2013). Poverty, Sustainabilty and Human Weilbeing:A social Welbeing Approach to the global fisheries Cisis Global enveromental change. Journal home page: wwwelsivier com/locate/cloenych

Doclus, Y. J., Arrar, A. \& Giles, J. (2009). Chronic and Transient Poverty: Measurement and Estimation, With Evidence from China. Journal of Development Economics, 9, 266-277.www/elsevier.com/devec.

Daniels. (2002). Poverty Alleviation in the Subsistenc Fisher Sector the South African. Journal of Economics, $7(5)$.

Danani, S. \& Islam, I. (2002). Poverty, Vulnerability and Social Protection in a Period of Crisis: The Case of Indonesia.Word development, 30(7),1211-1231.www.elsevier.com/locate/worlddev.

Degnbol, P. (2006). Painting the Floor with a hammer: tecnical Fixes in fisheries management. Marine Policy, 30(5), 534-543.

Denner, A. (2003). The Protective role of sosial capital and cultur norms in Latino communities a study of adolescent births. In.M.aguire Molina: A publik Health reader 373-390.San Francisco:Jossey.Bas

Ellis, G. F. R. (1984). The Dimensions of Poverty (DalamSosial Indicator Research

Ferdinand, A. (2000). Structural Equation Modeling in Management Research: Application in a Complex

Fao. (2005). Managing Fishing Capacity: a Review of Policy and Technical Issues.

Taringan, R. (2013). Economy, theory and application of mold seventh Earth Literacy publisher PT Jakarta

Umar. (2004). The Dimension of Poverty Application, social indicator Research. Model Model Research for Thesis and Dissertation S2 S3.

Agency Publisher FAO. (2012). Managing Fishing Capacity: a Review of Policy and tecnicalissues

Gainer, B. (2010). The Relationship Between Market-oriented Activities and Market-oriented Cultur; implications for The Development of Market orientation in non profit service organizations.Green, Maia and Hulme, D.2005.From Correlates and characteristic to Causes: Thinking About Poverty from a Choric Poverty Perspective. World Development, 30(6), 867-879. 
Gordon, H. S. (1954). The economic Theori of a common Property Resourses.TheFishery.

Giffin. (1999). Cultur and Economic Growth.European.

Mc.Gregor. (2008). Welbeing Poverty and ConflicWeD Policy briefing 01/08.

Godwin, K. (2010). Effects of climate Variability on thrre Fishing economic in high latitude region, Implikation for Fisher

Gozali, I. (2009). Structural Equation Modeling Concepts Theory and Applications with Lisrel.Universita program Diponegoro Semarang in Indonesia.

Hair, J. F. Jr., Rolph, E. A., Romald. L. T. \& William , G. B. (1998). Multivariate Data Analysis, Fifth Edition, New Jersey: Prentice-Hall International, Inc

Solimun. (2002). Stuctural Equation Modeling Concepts Theory and Application.

Soemardjan. (1984). Cultural Competence in the Assesment of poor in the rural United States.

Hancook, U. T. (2010). Cultural Competence in the Assesment of Poor Mexican families in the Rural Southeastern United States.

Mikolic, V. (2009). Cultur and languageawareness in the multicultural envirionment of Slovene Istria.

Mckay, A. \& Lawson, L. (2003). Assesing the Exten and Nature of Cronic Poverty in Low Income Countries: Issue and Evidence. World Development, 31(3), 425-439. 2003.

Milbourne, P. (2004). The local Geografhies of poverty: a rural ease-study. Geoforum, 35, 559 557.www,elseiver.com/locate/go forum.

Marquis, H. M. (1996). Erratum toNote on Cyclical Employment in the Consumtion gods sector.

Mahsen, J. \& Waters, W. F. (2002). Rural Poverty Ecuador: Assesinglokal Realities for The Development of ant Poverty Program. Word Development, 30(1), 33-47,2002.www elseiver science ltd. All right reserved

Munir, R. (2002). Regional Autonomy and Economic Inequality Issues, http; // www - inovasi.or.id.

Nurkses. (1953).Teori of poverty.Vicious circle.

Poli. (2007). Poverty and Solution, issues, http; //www tiny house of poverty. 